\title{
A search for a correlation between time change in transfer functions and seismic energy release in northern Taiwan
}

\author{
Kuang-Jung Chen ${ }^{1}$, Bonbbon Chiu ${ }^{1}$, and Cheng-Horng Lin $^{2}$ \\ ${ }^{1}$ Department of Earth Sciences, National Taiwan Normal University, Taipei, Taiwan 116, ROC \\ ${ }^{2}$ Institute of Earth Sciences, Academia Sinica, Taipei, Taiwan, ROC
}

(Received September 17, 2005; Revised December 18, 2005; Accepted February 5, 2006; Online published September 16, 2006)

\begin{abstract}
The geomagnetic data of the Lunping Geomagnetic Observatory from 1988 to 2000 are utilized for computing daily geomagnetic transfer functions. The method of analysis is based on the power spectrum analysis developed by Everett and Hyndman. Monthly means are statistically obtained from these daily values of transfer functions. In order to compare these time changes with seismic activity (seismicity), the earthquakes occurring within 150 $\mathrm{km}$ from Lunping, with a magnitude $M_{L}$ greater than 4.0, are located. The related energy releases by those earthquakes, summed month by month, are correlated to the transfer functions. After removing the seasonal effect, we find that the time changes of magnitude of $A_{u}$ and $B_{u}$ (real parts of the transfer function) for frequencies of $2,3,4$, and 6 cycles/hour seem to be strongly related to the energy release within the whole study period. Two significant precursors were found from the A and B values, 40 and 20 months before high seismicities, respectively.
\end{abstract}

Key words: Transfer function, seismic energy release, Taiwan.

\section{Introduction}

The conductivity of rocks is an important physical property which can be measured in the Earth. The temporal variation of conductivity underground has been related to earthquake occurrence in some earthquake prediction theories. One well-known model of earthquake mechanism is called the 'dilatancy' model, which proposes that the increased volume in stressed rock produces a large increase in porosity and mechanical permeability (Scholtz et al., 1973; Scholtz and Kranz, 1974). When electrolytic water permeates the pores and cracks, the conductivity of rock can increase significantly. Apart from the 'dilatancy' model, there are other reasons, such as a rise in temperature, that may also lead to noticeable increasing of conductivity within the rock in an earthquake preparation zone.

In earthquake prediction practice, detecting the time change of geomagnetic transfer functions is available for monitoring the possible conductivity change in the crust or upper mantle. The first two reports on this subject were published by Yanagihara (1972) and Miyakoshi (1975). Yanagihara and Miyakoshi studied the time changes in geomagnetic transfer functions which are considered to be associated with the 1923 Kanto earthquake with a magnitude of 7.8 and the Tashkent earthquake with a magnitude of 5.0. Later, similar and more precise works concerned with other earthquake occurrences can be found in the literature of Yanagihara and Nagano (1976), Rikitake (1979), Honkura (1979), Sano (1980), Shiraki (1980), Chen (1981), Gong (1985), Fujita (1990) and Chen and Fung (1993). Anoma-

Copyright (c) The Society of Geomagnetism and Earth, Planetary and Space Sciences (SGEPSS); The Seismological Society of Japan; The Volcanological Society of Japan; The Geodetic Society of Japan; The Japanese Society for Planetary Sciences; TERRAPUB lous electromagnetic precursories to earthquakes have been reported in many papers (e.g. Beamish, 1982; Rikitake, 1987a, b, 1997; Fraser-Smith et al., 1990; Yoshino et al., 1993; Oike and Murakami, 1993; Fujinawa and Takahashi, 1994; Pulinets, 1998; Liu et al., 2000; Zeng et al., 2001, 2002; Nagao et al., 2002; Yen et al., 2004).

Research on the relation between the time change of conductivity and seismic activity is an important subject in earthquake prediction. The conductivity change can be observed by artificial source DC sounding, but the sounding depth is not enough compared to the depth of focus of an earthquake. Deeper sounding in the crust or upper mantle can be carried out either by magnetotelluric sounding or by geomagnetic sounding. Therefore, detecting the time change of transfer functions in short-period geomagnetic variations is an available method for monitoring the possible conductivity change in the crust or upper mantle.

The concept of transfer functions comes from an empirical relation

$$
\Delta Z=A \Delta H+B \Delta D,
$$

where $\Delta D$ is the variation of magnetic declination, $\Delta H$ and $\Delta Z$ are the variations of horizontal and vertical components, respectively, and the coefficients $\mathrm{A}$ and $\mathrm{B}$ are called transfer functions, which are complex and frequencydependent.

Some results regarding the time changes in transfer functions related to seismic activities have been reported by many authors during the last 20 years (Yanagihara, 1972; Yanagihara and Nagano, 1976; Xu et al., 1978; Rikitake, 1979; Niblett and Honkura, 1980; Shiraki, 1980; Chen, 1981; Chen and Fung, 1985, 1990, 1993; Gong, 1985; Fujita, 1990; Fujiwara and Toh, 1996). The most important of these reports was that of Yanagihara (1972), who found 


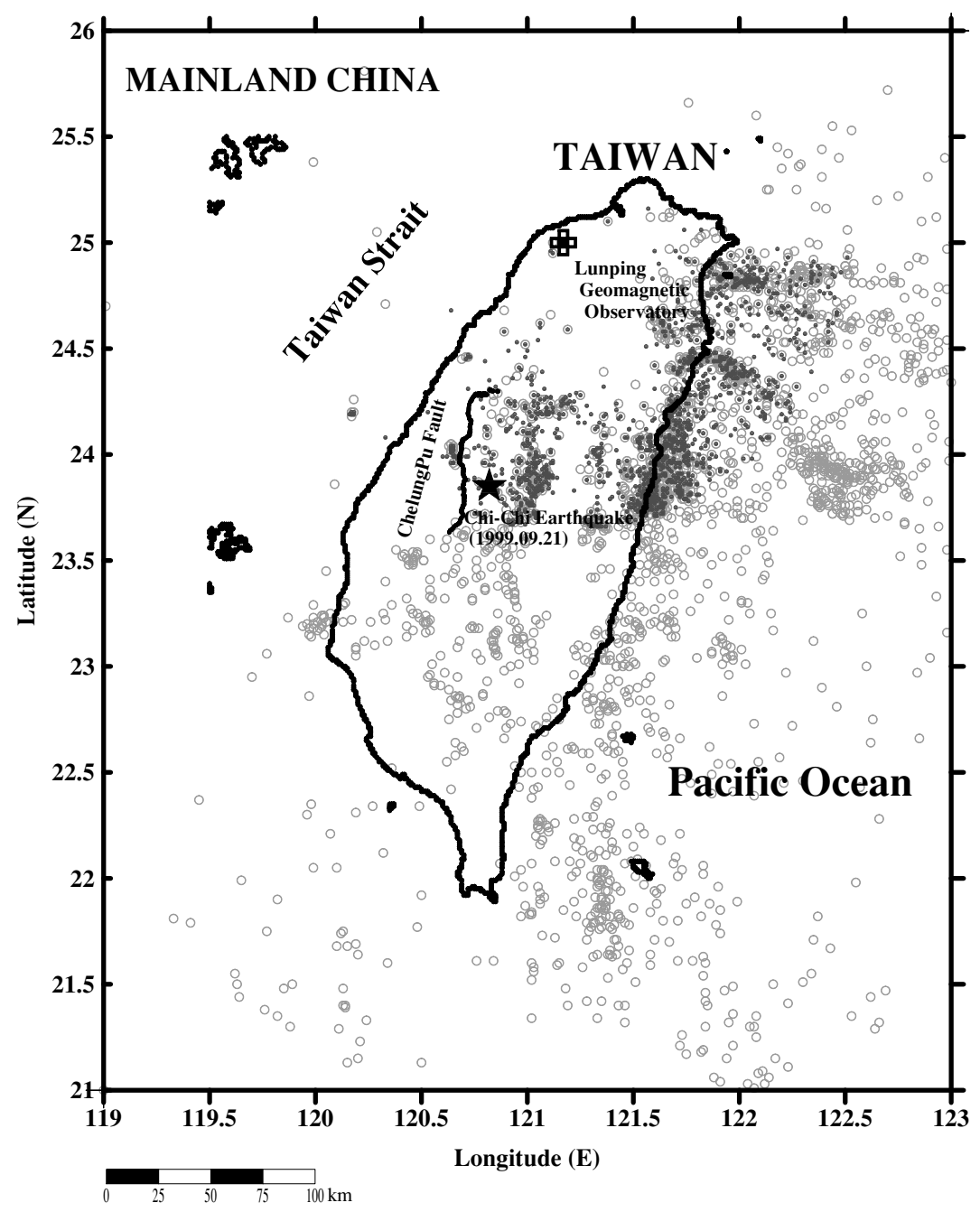

Fig. 1. The location of the Lunping Observatory and the earthquakes that occurred during 1988 and 2000 , with a magnitude $\left(M_{L}\right)$ greater than 4.0 within $150 \mathrm{~km}$ distance from Lunping. Gray circles denote the events with magnitude $M_{L}$ greater than 3.5 that occurred in the Taiwan area in the same period. The epicenter of the major event of the 1999 Chi-Chi earthquake and its coseismic fault, the ChelungPu fault, with surface rupture of more than $100 \mathrm{~km}$, is also shown.

quite a remarkable secular change in transfer function A at the Kakioka Magnetic Observatory associated with the large earthquake $(M=7.8)$, which occurred in 1923 near Tokyo. In that example, value A decreased to a minimum before the earthquake and more rapidly recovered after the minimum.

In this study, the geomagnetic data of Lunping Observatory $\left(121^{\circ} 10^{\prime} \mathrm{E}, 25^{\circ} 00^{\prime} \mathrm{N}\right.$, in Taiwan, see Fig. 1) were used to search for a possible relation between the time change in transfer functions and earthquake occurrences because the Taiwan region is an active seismic zone. The gray circles in Fig. 1 denote the earthquakes that occurred during the study period with magnitudes greater than 3.5. The solid dots represent the events used for energy analysis. The geomagnetic data from 1988 to 2000 for the Lunping Observatory in the Taiwan region have been analyzed using a simple method (Everett and Hyndman, 1967), which is adequate for single stations and has been used by many researchers (e.g., Honkura, 1979; Shiraki, 1980; Chen, 1981; Fujiwara and Toh, 1996). This method measures, directly, the maximum amplitudes of $\Delta H, \Delta D$, and $\Delta Z$ for each individual disturbance event, while $\Delta H, \Delta D$ and $\Delta Z$ are, respectively, the variations of horizontal, the declination, and the vertical component. Moreover, the spectral analysis method was employed for determining the complex transfer functions for the Lunping data from 1988 to 2000.

\section{Data Analysis}

The magnetic data of the Lunping Observatory, a unique permanent observatory with a triaxial fluxgate magnetometer in the Taiwan area, from 1988 to 2000 were utilized for the analysis in this paper. To keep the sensor temperature constant, the sensors have been housed in a heat-insulating box made from Polylon. Within the box, a heating device is installed to keep the temperature at $25 \pm 0.1^{\circ} \mathrm{C}$. The temperature of the sensors was controlled to within $\pm 0.5^{\circ} \mathrm{C}$, after the installation of the thermostat system. The temperature effects of each potentiometer is $-0.302,-0.973$, and $-0.096 \mathrm{nT}^{\circ} \mathrm{C}^{-1}$ for the $Y, X$, and $Z$ component resistors, respectively. Timing accuracy is within $3 \mathrm{sec}$ (Huang, 1990).

The raw data of the three components of geomagnetic variations were inspected and the geomagnetic short-period disturbances that have durations from 1024 to $4096 \mathrm{~min}$ 


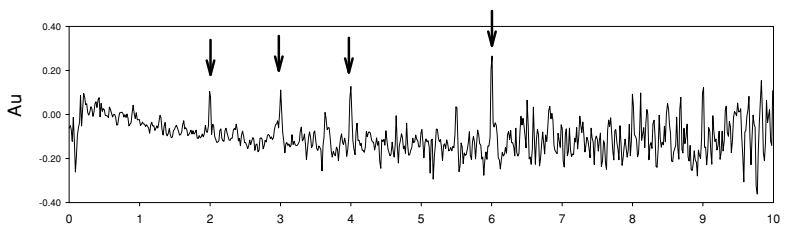

(b)

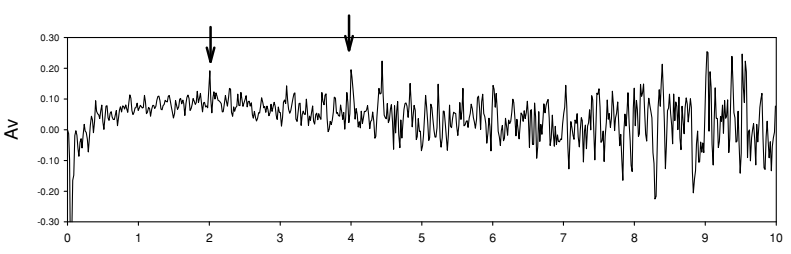

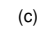

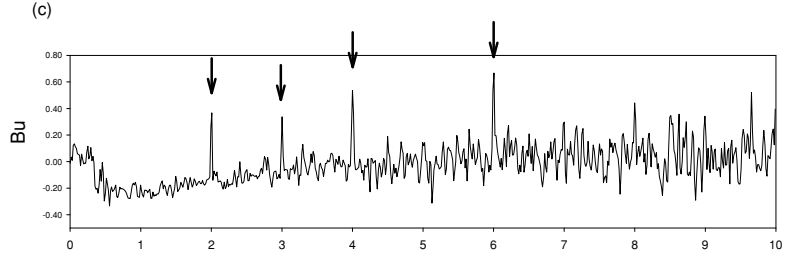

(d)

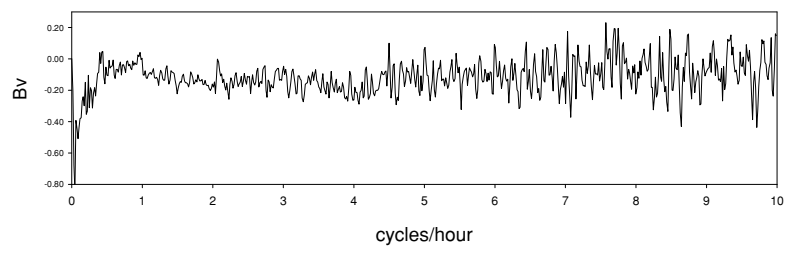

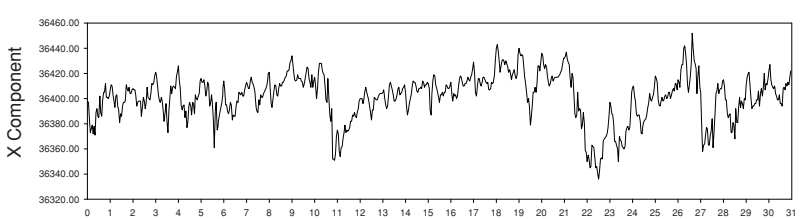

(f)

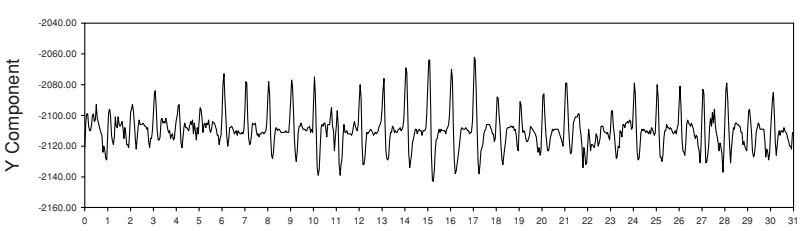

(g)

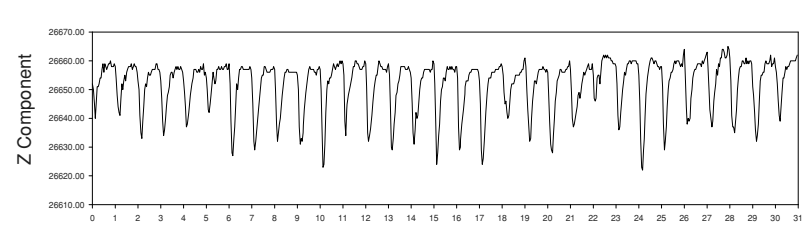

(h)

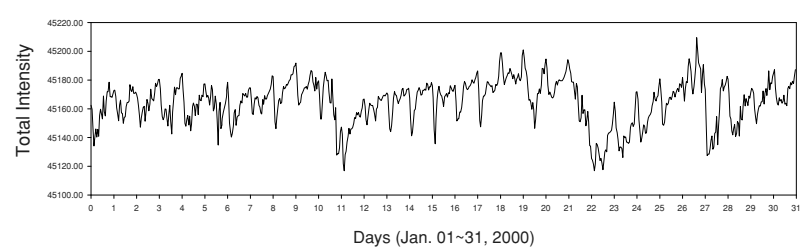

Fig. 2. Transfer functions (a) $A_{u}$, (b) $A_{v}$, (c) $B_{u}$, and (d) $B_{v}$ calculated, respectively, to different frequencies from the Lunping Observatory for one-month data (January 2000). Magnetograms of (e) $X$ component, (f) $Y$ component, (g) $Z$ component, and (h) total intensity.

Table 1. The earthquakes occurred within $200 \mathrm{~km}$ from stations ASP, WNG, and KYC during 1988 to 2001 with magnitude $M_{L} \geq 3.0$ (located by Incorporated Research Institutions for Seismology (IRIS)).

\begin{tabular}{ccc}
\hline Relative to stations & Date & $M_{L}$ \\
\hline ASP & $1991 / 04 / 18$ 04:51:05 & 3.1 \\
ASP & $1991 / 11 / 28$ 04:18:59 & 3.1 \\
ASP & $1996 / 07 / 19$ 14:14:55 & 3.5 \\
ASP & $1998 / 06 / 16 ~ 15: 12: 58$ & 3.2 \\
WNG & $1997 / 11 / 1905: 15: 38$ & 4.3 \\
WNG & $1998 / 12 / 2608: 32: 09$ & 3.4 \\
YKC & $1990 / 03 / 3007: 53: 54$ & 3.5 \\
\hline
\end{tabular}

were chosen for analysis. The values were recorded in digital form on magnetic tapes. Linear detrending, highpassing (cut-off period of $200 \mathrm{~min}$ ) and a Hanning window were applied to each portioned data set. Auto- and crosspower spectra for each data segment were calculated using an FFT, and smoothed in frequency. The transfer functions of frequencies from 0.1 to 10 cycles/hour were obtained according to the formula introduced by Everett and Hyndman (1967) based on the least-square method:

$$
A=\frac{(\bar{P} W-\overline{Q S})}{(N W-S \bar{S})}, \quad B=\frac{(\bar{Q} N-\bar{P} S)}{(N W-S \bar{S})},
$$

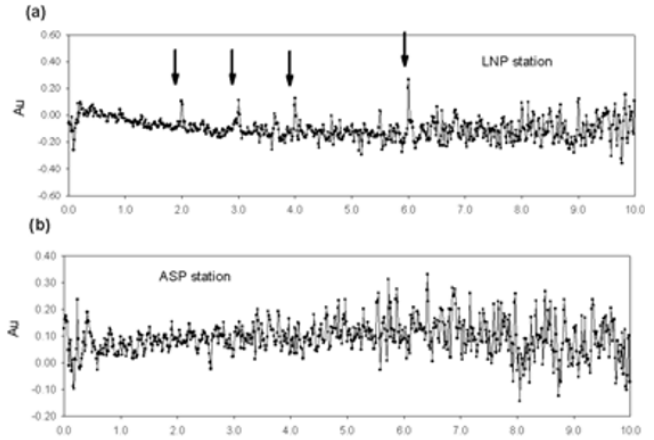

(c)

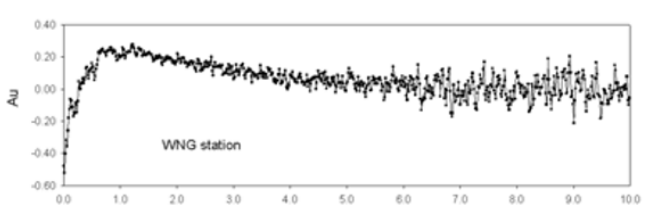

(d)

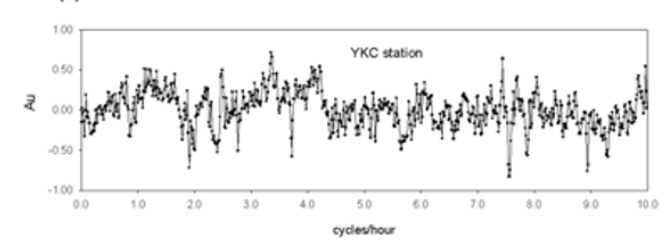

Fig. 3. Transfer functions $\left(A_{u}\right)$ calculated respective to different frequency from stations (a) Lunping, (b) ASP, (c) WNG, and (d) YKC for one month data (January 1998). 
(a)

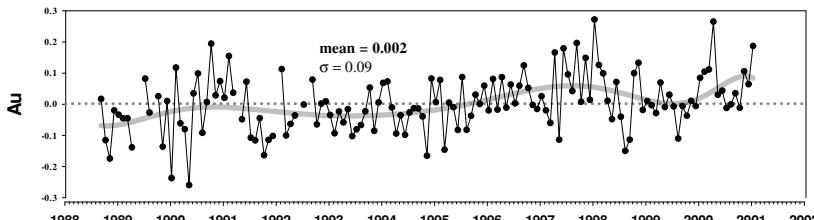

$\begin{array}{lllllllllllllll}1988 & 1989 & 1990 & 1991 & 1992 & 1993 & 1994 & 1995 & 1996 & 1997 & 1998 & 1999 & 2000 & 2001 & 2002\end{array}$

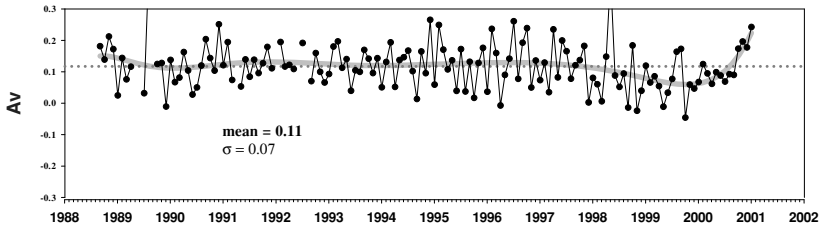
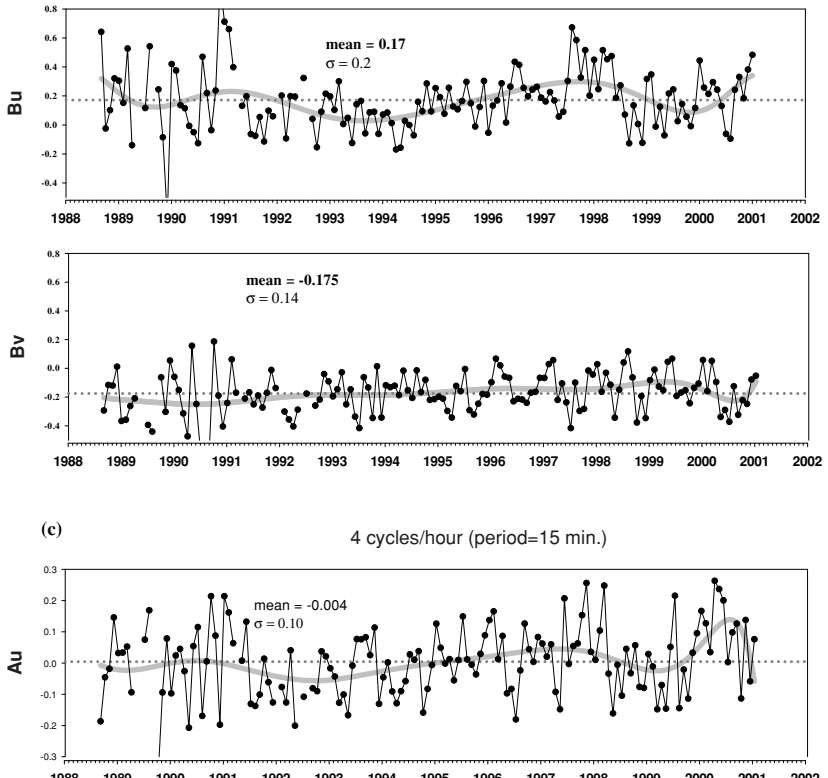

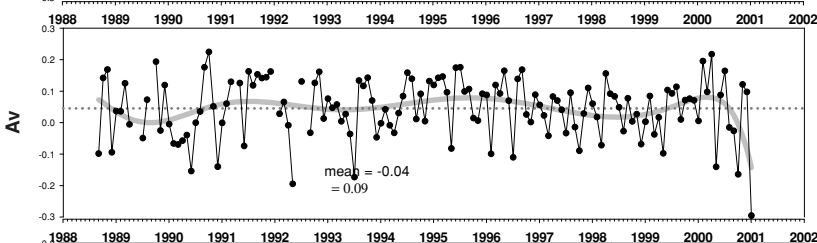
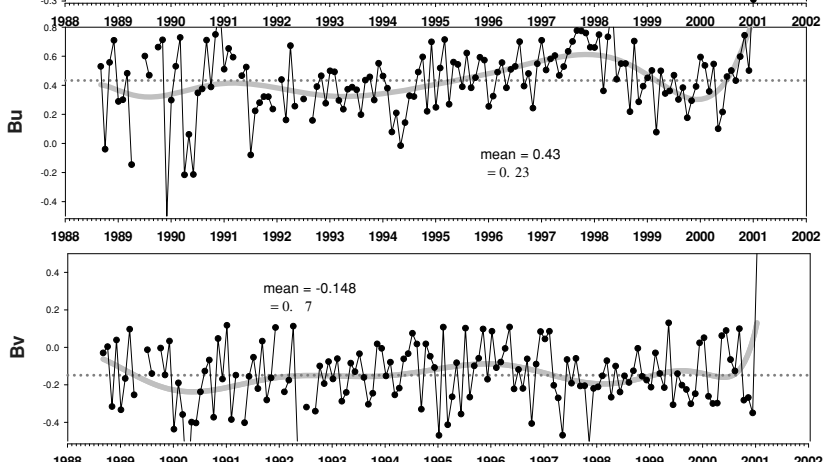

(b)

3 cycles/hour (period=20 $\mathrm{min}$.)
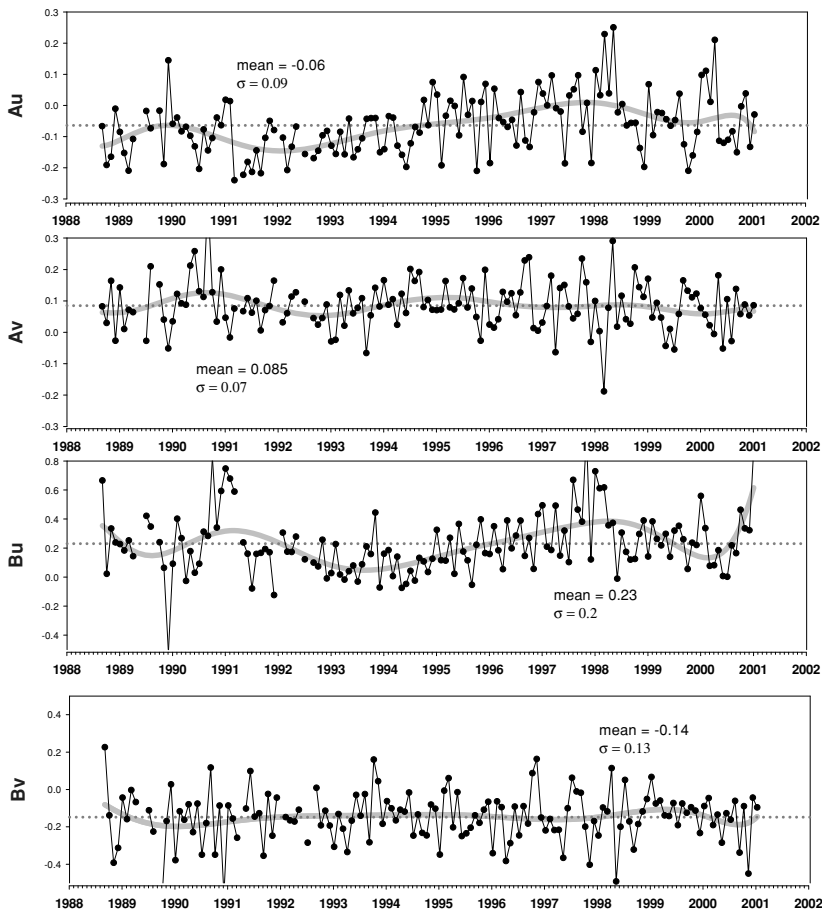

(d) 6 cycles/hour (period=10 $\mathrm{min}$.)
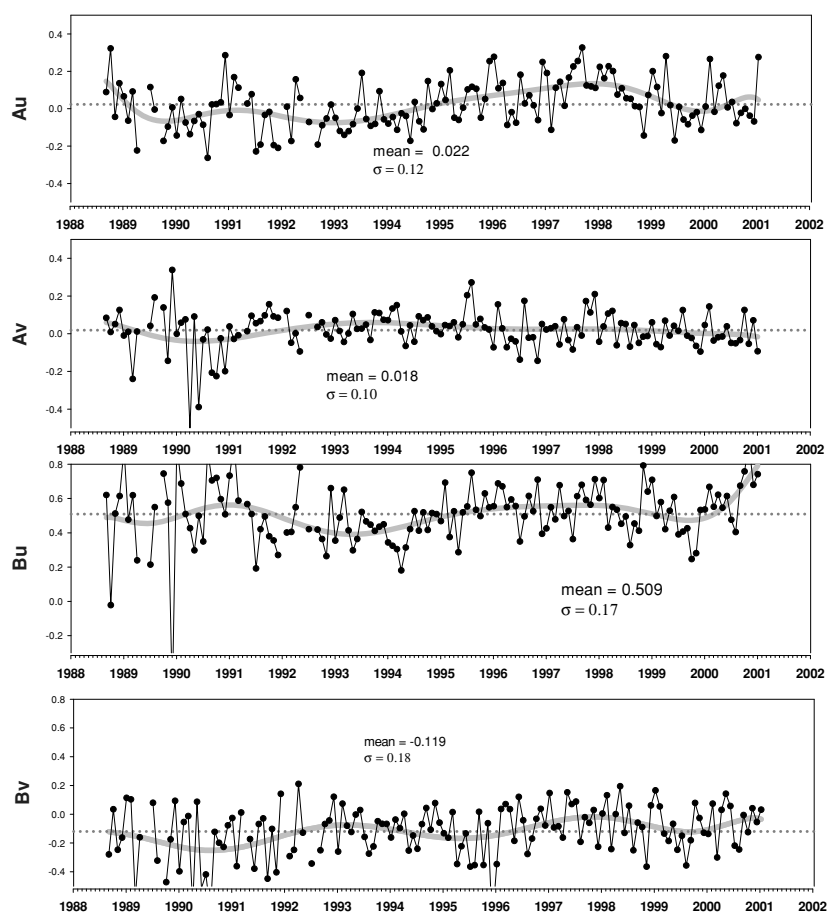

Fig. 4. Time changes in transfer functions $\left(A_{u}, A_{v}, B_{u}\right.$, and $B_{v}$ ), at (a) $30 \mathrm{~min}$, (b) $20 \mathrm{~min}$, (c) $15 \mathrm{~min}$, (d) $10 \mathrm{~min}$. The bold solid lines in each curve represents its regressions.

where

$$
\begin{aligned}
& N=\sum_{1}^{n} X_{r} \bar{X}_{r}, P=\sum_{1}^{n} X_{r} \bar{Z}_{r}, W=\sum_{1}^{n} Y_{r} \bar{Y}_{r}, \\
& Q=\sum_{1}^{n} Y_{r} \bar{Z}_{r}, S=\sum_{1}^{n} X_{r} \bar{Y}_{r},
\end{aligned}
$$

while $X, Y$, and $Z$ are the three components of the geomag- netic field, and overbars denote the complex conjugates.

These functions are generally complex functions and are written as

$$
\begin{aligned}
& A=A_{u}+i A_{v}, \\
& B=B_{u}+i B_{v} .
\end{aligned}
$$

Day-to-day calculation of the transfer functions were car- 
(a)

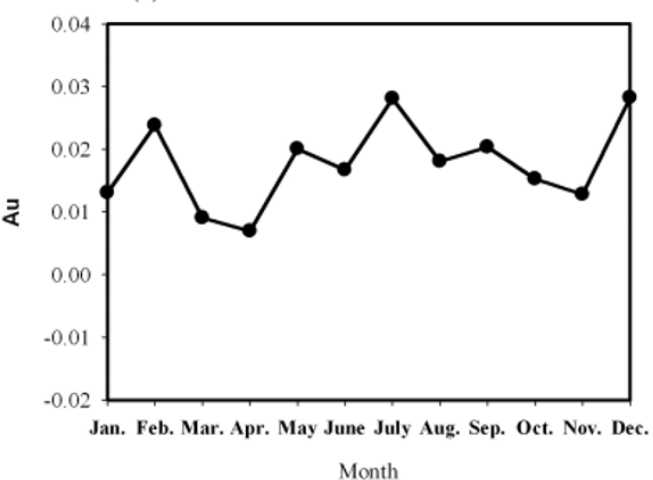

(c)

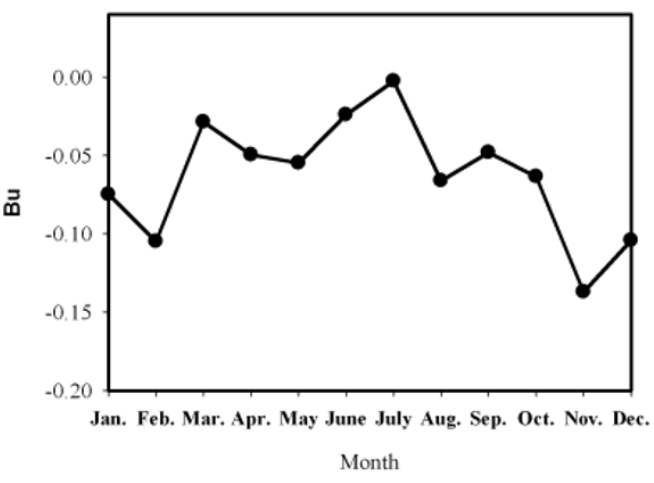

(b)

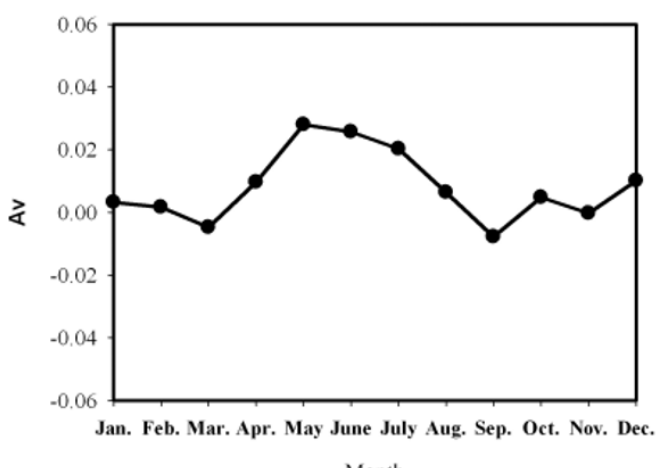

(d)

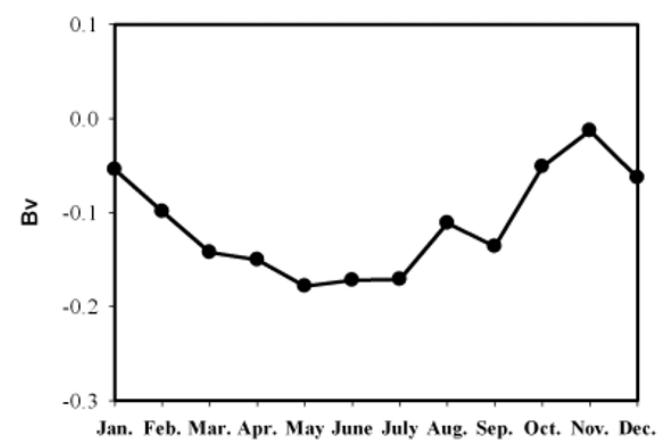

Lnp station

Month

Fig. 5. Seasonal variation of transfer functions (a) $A_{u}$, (b) $A_{v}$, (c) $B_{u}$, and (d) $B_{v}$ of the Lunping Observatory.

(a)

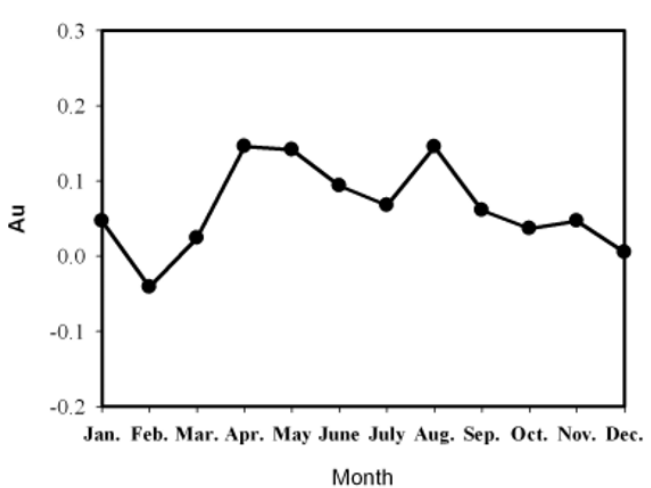

(c)

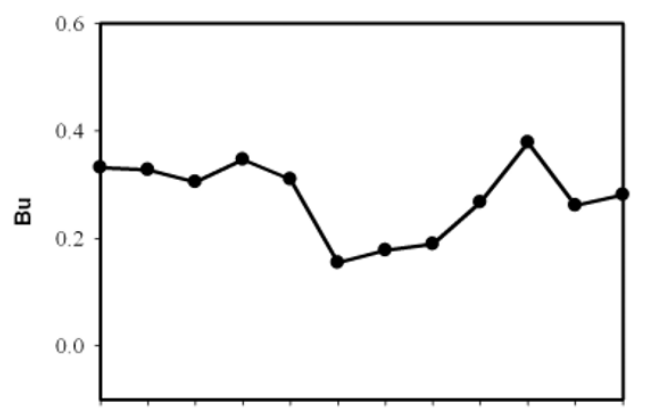

Jan. Feb. Mar. Apr. May June July Aug. Sep. Oct. Nov. Dec. Month (b)

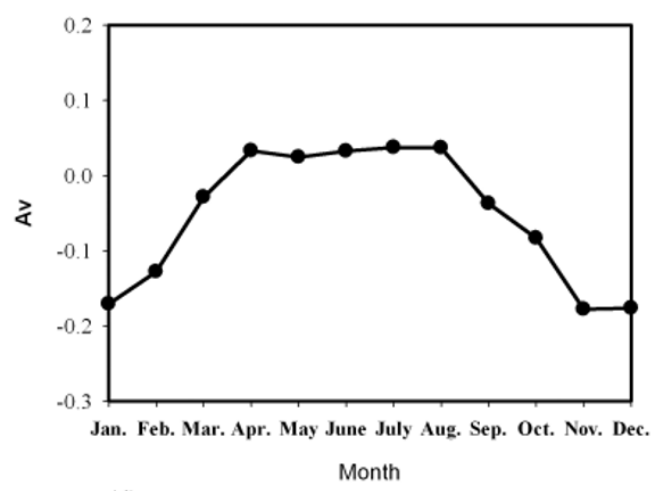

(d)

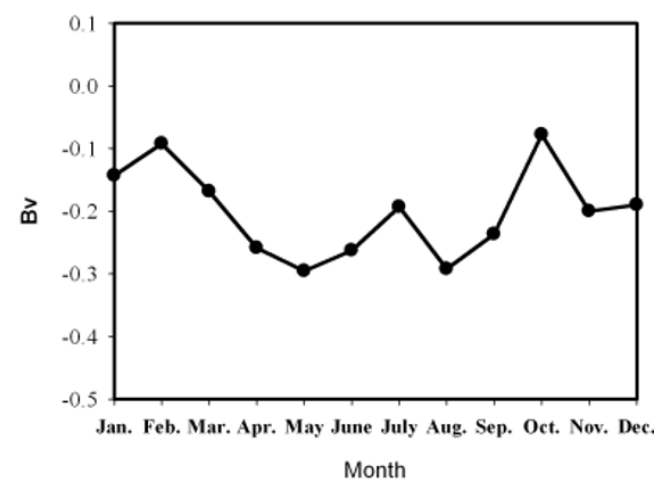

WNG station

Fig. 6. Seasonal variation of transfer functions (a) $A_{u}$, (b) $A_{v}$, (c) $B_{u}$, and (d) $B_{v}$ of the WNG Observatory. 
(a) Magnitude $>3.0$
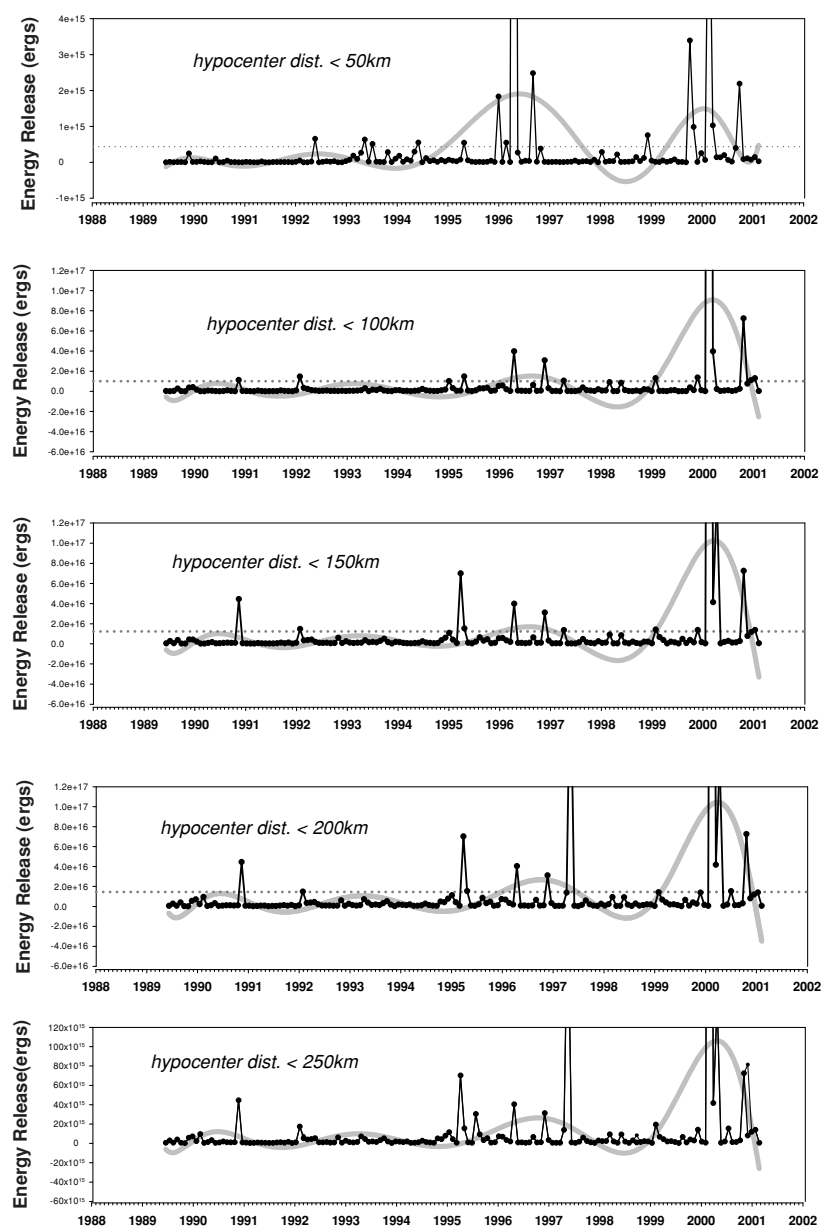

(b) Magnitude $>4.0$
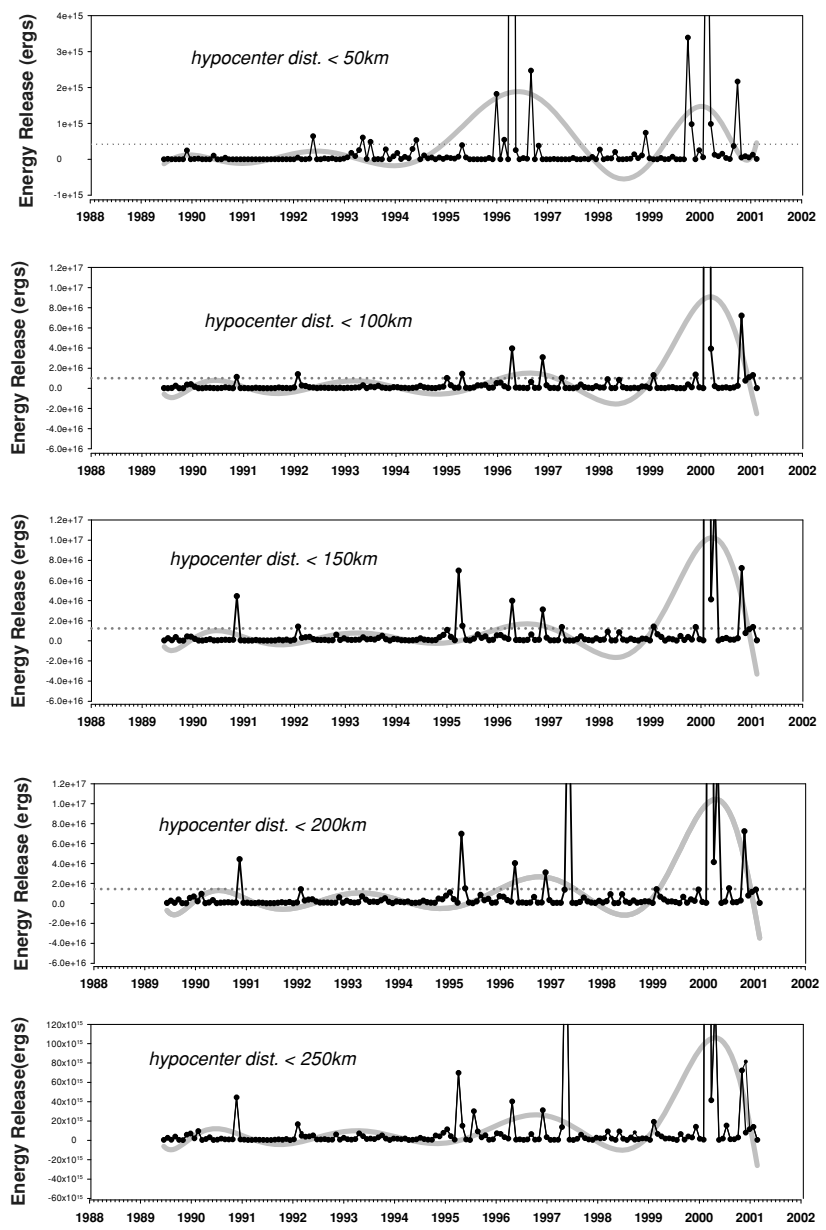

Fig. 7. Time changes of the monthly summation of energy released by earthquakes of a magnitude $\left(M_{L}\right)$ (a) greater than 3.0 , (b) greater than 4.0 , within a radius of $50,100,150,200$, and $250 \mathrm{~km}$, respectively (from top to bottom), from the Lunping Observatory. The bold solid lines in each curve represents its regressions.

ried out during the 13 years from 1988 to 2000, regardless of the degree of magnetic disturbance. Figures 2(a)(d) show the time change of transfer functions for one month (January 2000). Magnetograms used for analyses are also shown in the same figures (e)-(h). As clearly seen in Figs. 2(a)-(d), transfer functions change smoothly over the frequency range between 0.1 and 10 cycles/hour, but they are oscillatory at a high-frequency range. Four significant frequencies at 2, 3, 4, and 6 cycles/hour can be found. These statements generally hold true for other months. If the day-to-day scatter of transfer functions is random, it can be eliminated, to a certain extent, by taking averages, though the time resolution of changes as a precursor would be reduced as a result. However, it was found from a detailed examination that the scatter is not random. Geomagnetic data from three geomagnetic observatories in the "seismic quiet" area (earthquakes occurred with magnitude greater than $M_{L} 3.0$, within $200 \mathrm{~km}$ from these stations are listed in Table 1) are selected and analyzed. The results for these three stations ASP (Alice Springs, Australia, $133^{\circ} 53^{\prime} \mathrm{E}, 23^{\circ} 46^{\prime} \mathrm{S}$ ), WNG (Wingst, Germany, $90^{\circ} 4^{\prime}$ E, $53^{\circ} 45^{\prime} \mathrm{N}$ ), and YKC (Yellow Knife, Canada, $245^{\circ} 30^{\prime} \mathrm{E}$, $62^{\circ} 30^{\prime} \mathrm{N}$ ) are shown in Figs. 3(b)-(d) to examine the particular frequencies 2, 3, 4, and 6 cycles/hour. Comparing the variation in LNP (Fig. 3(a)) to those in these stations, we can easily find that all three stations in the "seismic quiet" area (less than 4 events $\left(M_{L} \geq 3.0\right)$ within 13 years, see Table $1)$, didn't show any significant frequency. In other words, the frequencies 2, 3, 4, and 6 cycles/hour that exist in the Lunping station are extremely particular.

The monthly average of transfer functions from 1988 to 2000 were plotted against time, as shown in Fig. 4. Looking at Figs. 4(a)-(d), it appears that part of the change in transfer functions seems to be ascribed to seasonal change. The seasonal effect can also be found in many areas (Shiraki, 1980; Chen, 1981; Gong, 1985; Chen and Fung, 1993). In order to examine this seasonal influence, the transfer functions summed with the all-frequency range of the same month were averaged over 8 years from 1993 to 2000 . The result is shown in Fig. 5, which indicates that $A_{u}$ and $B_{u}$ are small in winter and large in summer. This is consistent with the seasonal change of $A_{u}$ and $B_{u}$ in Shiraki's article (1980). The data of station WNG (Wingst) was processed using the same method and same period is shown in Fig. 6. It is obvious that the variation pattern is quite similar to those in LNP except for $B_{u}$. The seasonal effect varies from 0.03 (for $A_{u}$ ) to 0.2 (for $B_{v}$ ). The existence of such a seasonal change implies that part of the variation in transfer func- 
(a)
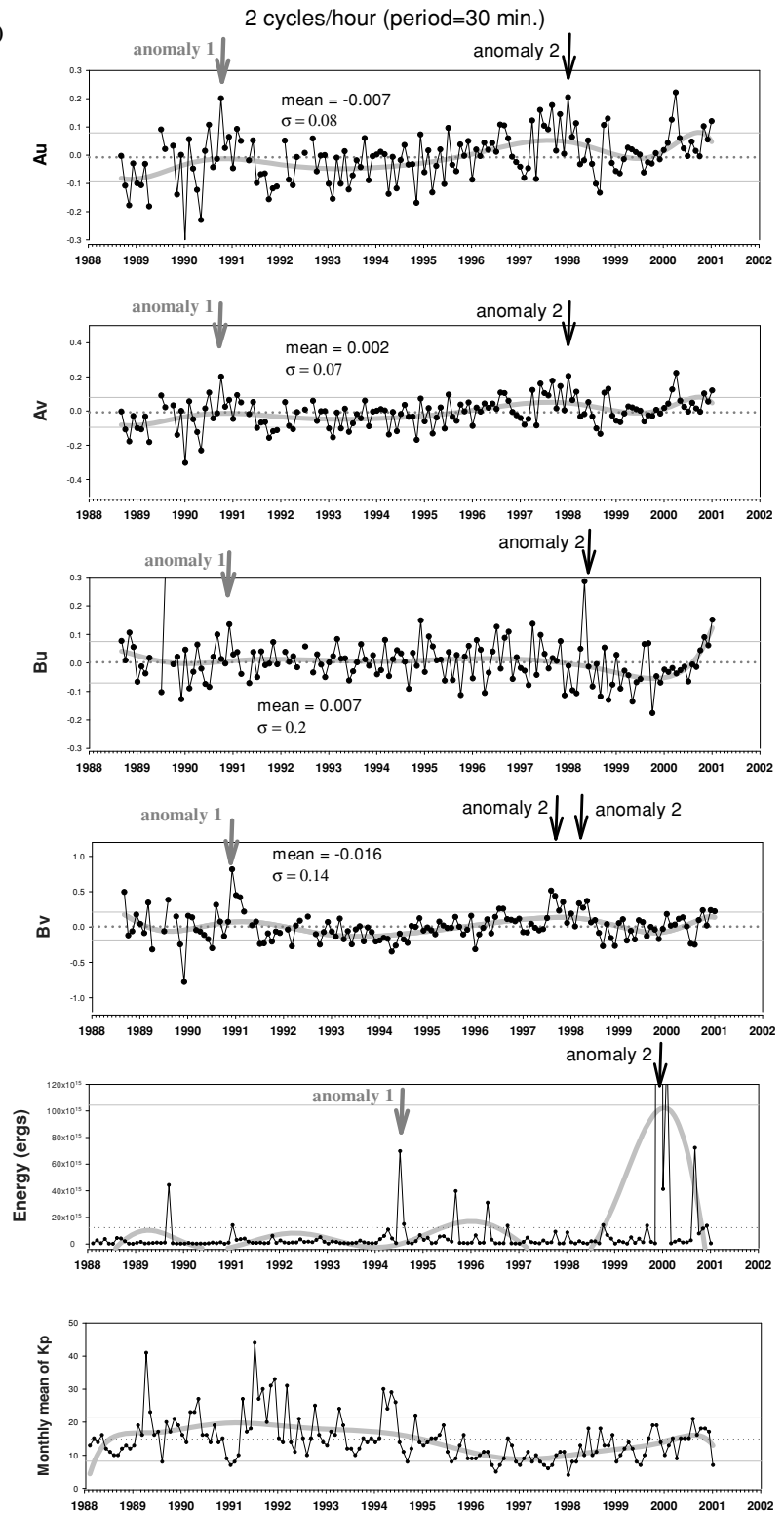

(b)
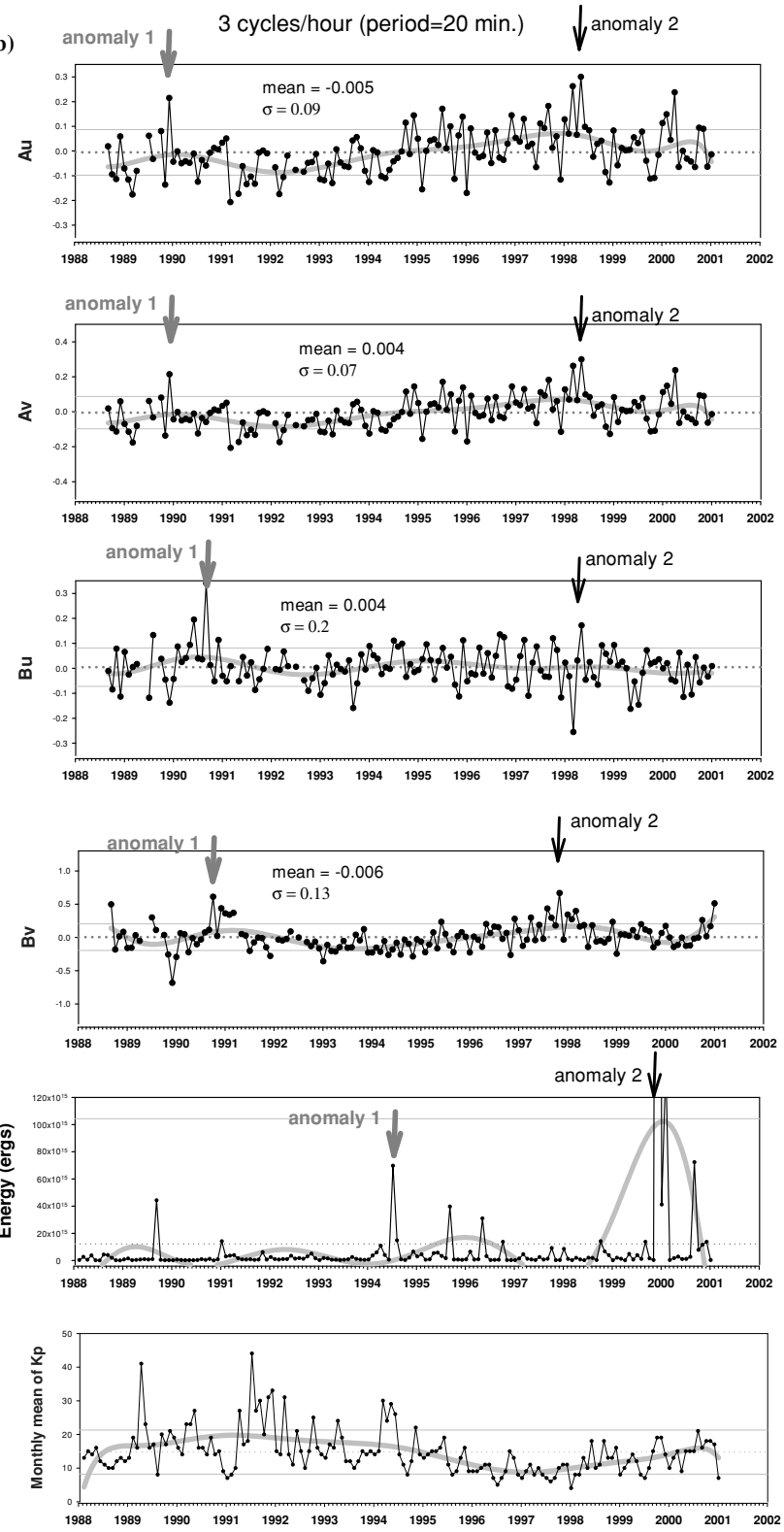

Fig. 8. Transfer functions after removing the seasonal effects calculated for periods of (a) $30 \mathrm{~min}$, (b) $20 \mathrm{~min}$, (c) $15 \mathrm{~min}$, (d) $10 \mathrm{~min}$. Monthly summation of energy released by earthquakes of a magnitude $\left(M_{L}\right)$ greater than 4.0 within a radius of $150 \mathrm{~km}$ from the Lunping Observatory are shown at the bottom of each figure. The global geomagnetic activity index $(K p)$ (acquired from the National Geophysical Data Center (NGDC) for the study period is plotted at the bottom. The bold solid lines in each curves represent its regressions.

tions might be attributed to the influence of the change in external magnetic disturbance. It may be caused by the effects of seawater (coastal effect) and sediments nearby the station (Fujiwara and Toh, 1996).

In order to search for the correlation between the transfer functions and seismicities, earthquakes of magnitudes greater than 3.0 within a radius of $50 \mathrm{~km}$ of the Lunping Magnetic Observatory that occurred during the study period were collected from the Earthquake Catalogue of the Central Weather Bureau. The total energy release, estimated by the empirical relation $\log (E)=11.8+1.5 M_{L}$ (Gutenberg, 1956). Figure 7 shows the time changes of the monthly summation of energy released by earthquakes of magnitude with (a) $M_{L} \geq 3.0$ and (b) $M_{L} \geq 4.0$, within a radius of 50,100,150,200, and $250 \mathrm{~km}$, respectively (top to bottom), from the Lunping Observatory. These 10 vari- ation curves look similar to each other except for the first hump (between 1996 to 1997) shown within $50 \mathrm{~km}$ is higher than that of the others. However, they all show two significant anomalies in the figure. The hypocenter distance of the 1999 Chi-Chi earthquake for Lunping is about $160 \mathrm{~km}$. This implies that the seismic energy release affected by the 1999 Chi-Chi earthquake can be neglected if we set $150 \mathrm{~km}$ as the criterion for choosing the earthquake. After removing the seasonal effect, the monthly averages of the transfer functions with frequencies of 2, 3, 4, and 6 cycles/hour are shown with dots and lines in Fig. 8. The doted line denotes the horizontal axis and shows months relative to January 1988. In order to search for the correlation between the transfer functions and seismicities, we use the linear regression to fit all the curves in Fig. 8. The linear regression uses the least-squares method to construct the fit of a set of data 
(c)
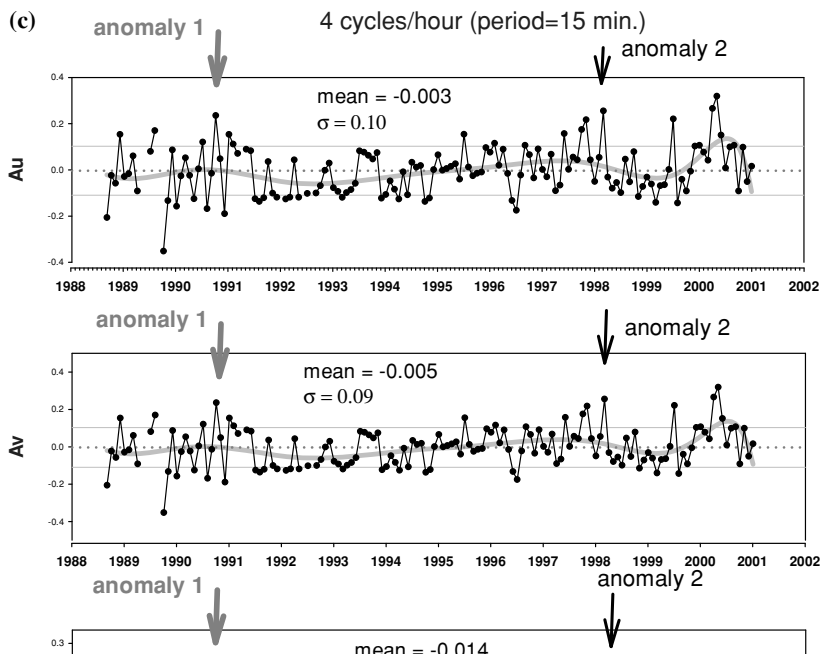

它
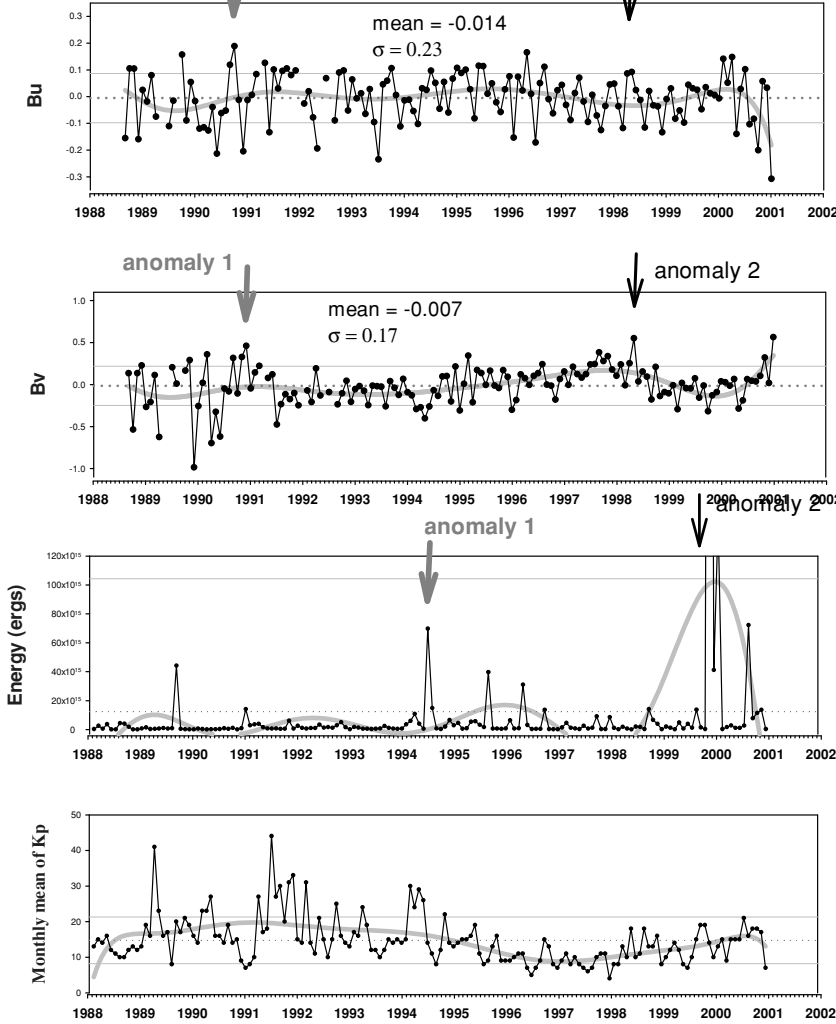

(d)
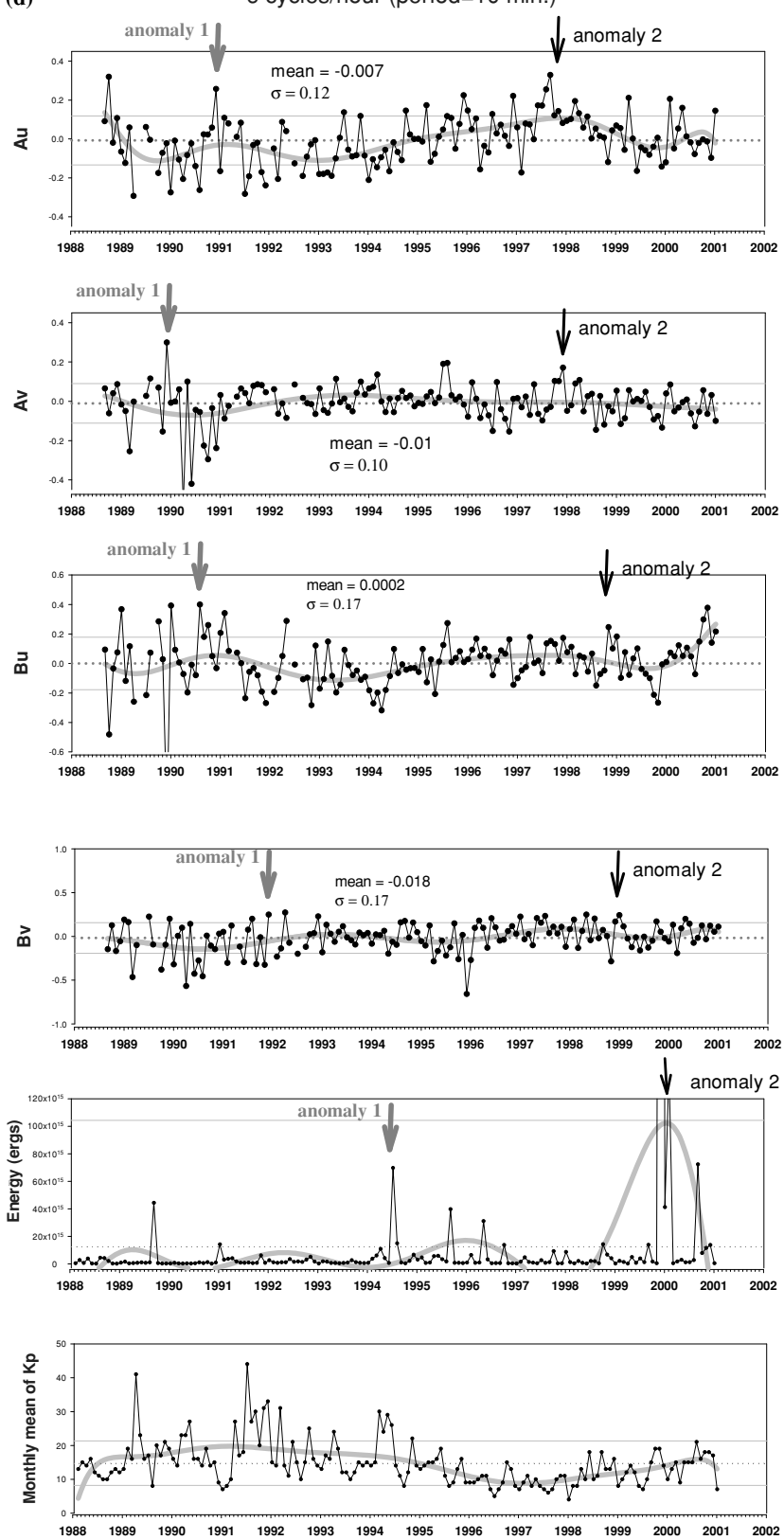

Fig. 8. (continued).

points $\left(x_{i}, y_{i}\right) i=1, \ldots, n$ by a polynomial of degree $p$ where

$$
y=\beta_{0}+\beta_{1} x^{1}+\beta_{2} x^{2} \cdots \beta_{p} x^{p} .
$$

The regression lines of these transfer functions are almost flat except that of higher seismicity periods. It seems that the trend of $\mathrm{A}$ and $\mathrm{B}$ is closely related to the energy release with a negative correlation. During a high seismicity period, the $\mathrm{A}$ and $\mathrm{B}$ values are larger than those during a low seismicity period. However, it should be noticed that the $\mathrm{A}$ and $\mathrm{B}$ values show two gentle increases (or two "anomalies", which are larger or smaller than one standard deviation) about 40 and 20 months before the high seismicity arrives. Examining the $B_{u}$ values of ASP and WNG stations of the same period (shown in Fig. 9), we find that they do not show the same precursors in the relative time which the LNP station shows.

\section{Concluding Remarks and Discussions}

Fujita (1990) found that the time variations in the monthly means of transfer functions are generally correlated among several observatories separately located (such as Memambetsu, Kakioka, and Kanoya), hence he concluded that the transfer functions are not adequate for shortterm earthquake prediction. However, Fujita pointed out that the annual change rates of the transfer functions might be meaningful for monitoring earthquake occurrences.

In this study, the measured A and B values at Lunping changed remarkably with two humps (anomalies 1 and 2 in Fig. 8), from 1991 to 1992 and from 1997 to 1998 (e.g., a variation in $A_{u}$ amounting to as much as 0.3 , i.e. more than twice the standard deviation (0.12)), as the arrows show in Fig. 8(d). We consider that these variations occur locally and the latter may be related to the 1999 Chi-chi earthquake 
(a)
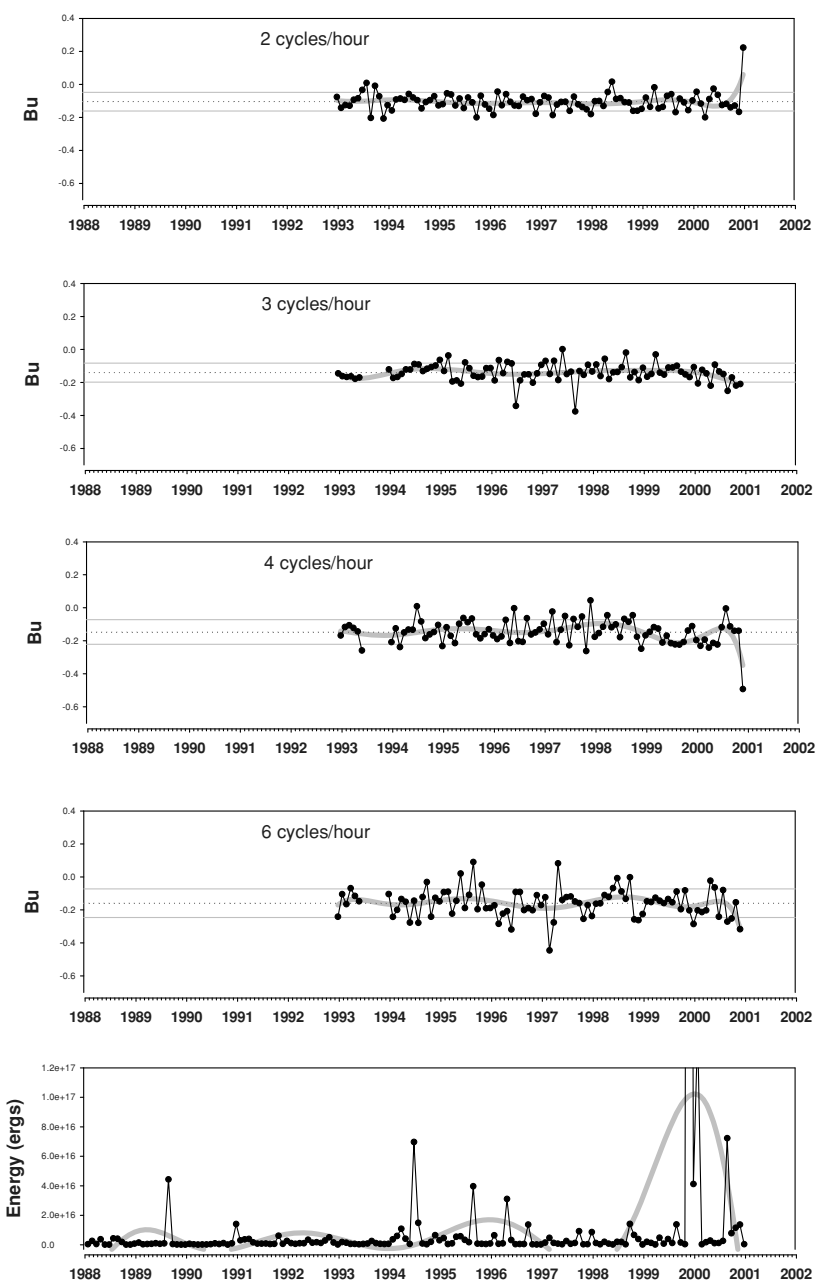

(b)

WNG station

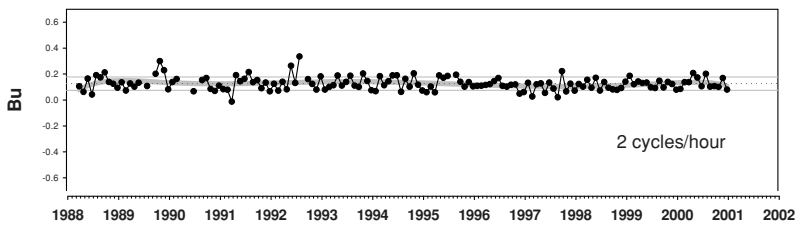

ฉ
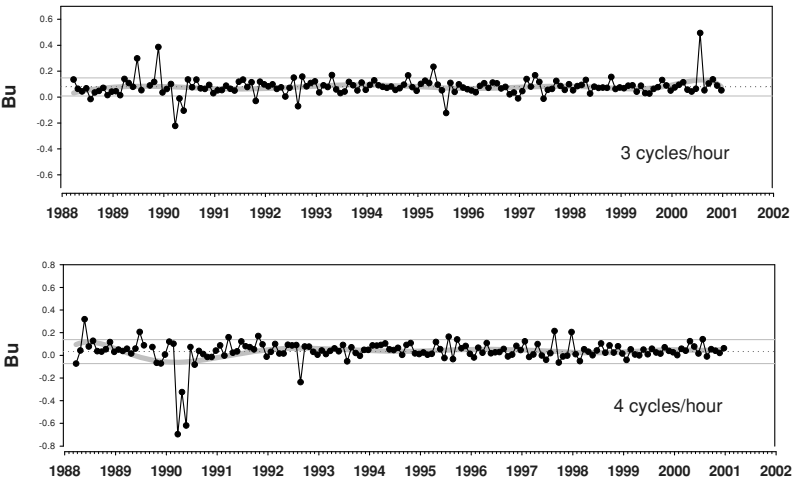

穴
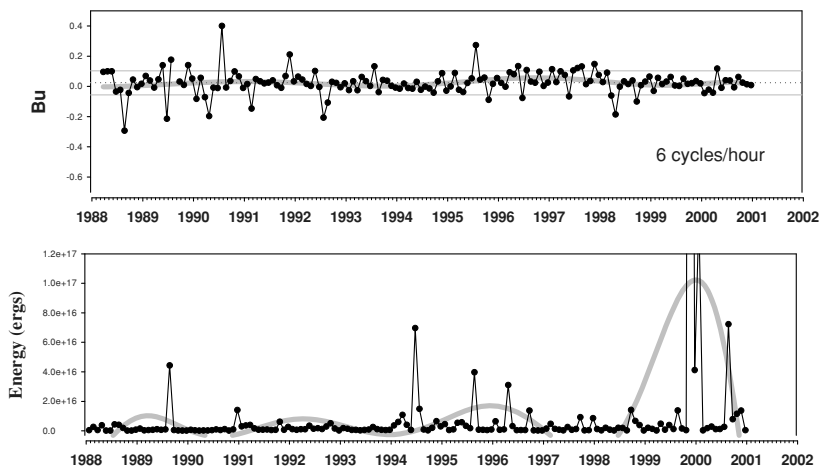

Fig. 9. Monthly average of $B_{u}$ at period $30 \mathrm{~min}, 20 \mathrm{~min}, 15 \mathrm{~min}$, and $10 \mathrm{~min}$, for station (a) ASP, (b) WNG, and (c) YKC.

occurrence (the second highest seismicity in Fig. 8). The global geomagnetic activity index $(K p)$ (acquired from the National Geophysical Data Center (NGDC) for the study period is plotted at the bottom of Fig. 8. It can be easily found that there is no significant correlation between $K p$ and the energy release in the Lunping area. For comparison, we introduce the time changes in transfer functions observed at the "seismic quiet" area of ASP, and WNG observatories. Figure 9 shows the month-to-month variations of the transfer functions in the same interval to that Fig. 8 shows. We can see that the time changes of transfer functions didn't show the same increases in the same periods at these stations. It can be concluded that the changes of $\mathrm{A}$ and B in Fig. 8 is a local effect rather than a global effect.

In searching for the correlation between transfer functions and seismic activity, most papers found a major anomaly in A (e.g. Yanagihara, 1976), while fewer in A and B (e.g., Rikitake, 1979). It is still hasty to discriminate which transfer function is more sensitive to seismic activity based on published papers or laboratory studies. In this study, most of the frequency components of A and B show correlations to seismic energy release, but not all (e.g., $B_{v}$ in 6 cycles/hour shown in Fig. 8).
The selection of nearby earthquakes is an important matter, because so many occurred in the Taiwan region during the study period (as Fig. 1 shows). Chen and Fung (1985) concluded that the imaginary Parkinson arrows can be affected by geomagnetic induction within $150 \mathrm{~km}$. The selection principle used here was to choose those earthquakes as near as possible (not larger than $150 \mathrm{~km}$ ) and as large as possible, but it is certainly not objective enough. The difference of energy release between that of magnitudes larger than 3.0 and larger than 4.0 of the earthquake catalogue (released by CWB) within the study period is quite small (as Fig. 7 show). If the distance is extended to $250 \mathrm{~km}$ from Lunping, the conclusion that a correlation exists between transfer functions and seismicity are still valid.

The seismic active region in our study period is southeastern (primarily attributed to the collision between the Eurasian and Philippine Sea Plates) and the central part (swarm of the 1999 Chi-Chi earthquake) of Taiwan. In the Taiwan area, the Lunping geomagnetic observatory is a unique permanent observatory with a triaxial fluxgate magnetometer. It might be better if there is a closer station to the seismic active region.

Finally, the transfer function estimates are averaged over 
(c)
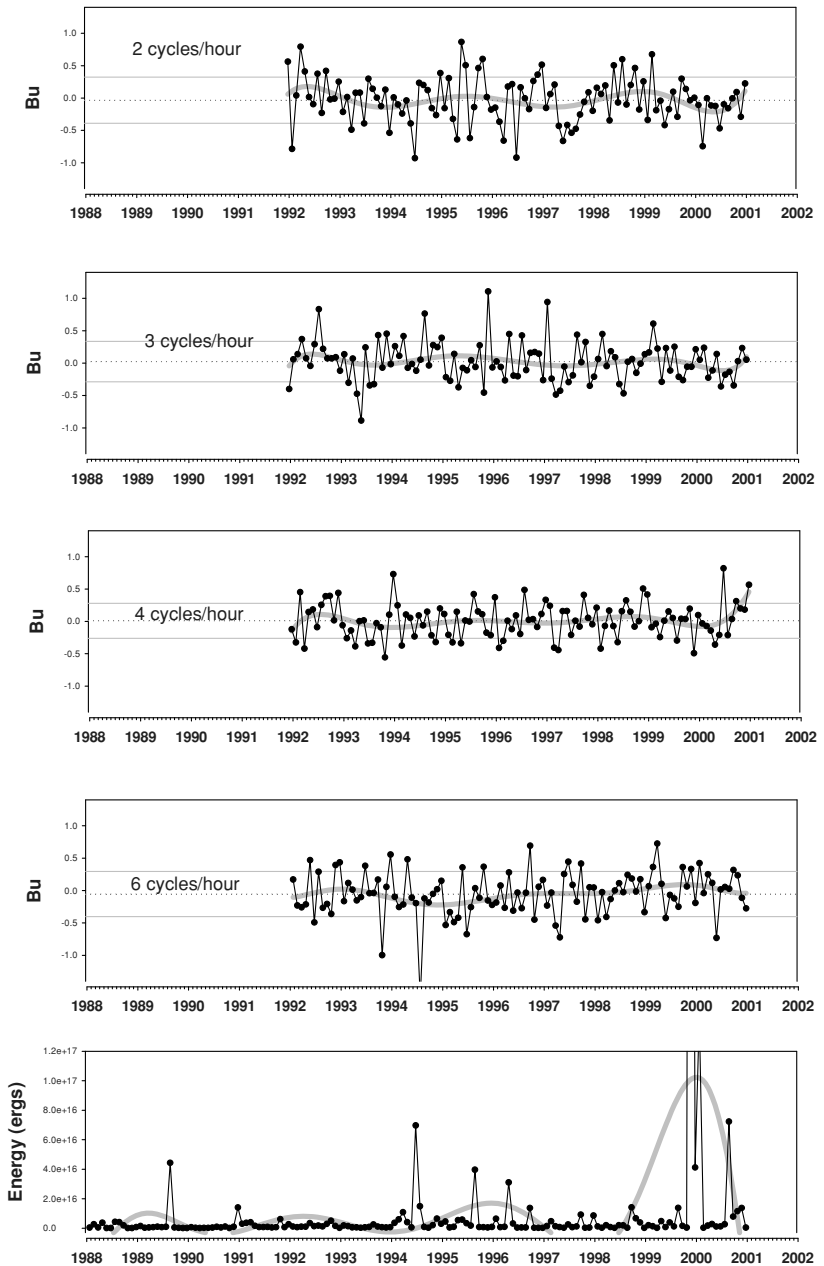

Fig. 10. (continued).

1-month intervals so that only fairly long-term precursory effects can be detected. In the Taiwan area, earthquakes occurring so frequently, estimates of 1-month interval are quite inappropriate to discover a single relationship between transfer function change and a single earthquake occurrence.

Acknowledgments. The authors are greatly indebted to Mr. Yung-Po Lee, for providing geomagnetic data of the Lunping Geomagnetic Observatory. The authors also wish to thank the staff of World Data Center A for continuously providing many digital magnetograms of the Alice Spring, Wingst (WNG), and Yellow Knife (YKC) observatories during the past several years. The authors would like to thank Prof. C. S. Wang and two anonymous reviewers for many useful comments and suggestions on the original manuscript. This work was supported by the National Sciences Council, ROC under the Grants NSC-91-2119-M-003-002 and NSC-92-2119-M-003-001.

\section{References}

Beamish, D., A geomagnetic precursory to 1979 Carlisle earthquake, Geophys. J. R. Astr. Soc., 68, 531-543, 1982.

Chen, P. F., A search for correlation between time change in transfer functions and seismic activity in north Taiwan, J. Geomag. Geoelectr., 33, 635-643, 1981.

Chen, P. F. and P. C. W. Fung, Significance of the sign changing of the imaginary arrows in geomagnetic induction investigation, Geophys. $J$.
R. Astr. Soc., 80, 257-263, 1985.

Chen, P. F. and P. C. W. Fung, Time changes in complex transfer functions at Lunping and the 1986 earthquake $\left(M_{S}=7.6\right)$ near Hualian, Proceedings of the International Symposium on Geomagnetism, edited by the Organizing Committee of Conference, pp. 81-85, Seismological Bureau of Shanghai, China 1990.

Chen, P. F. and P. C. W. Fung, Time changes in geomagnetic transfer functions at Lunping before and after the 1986 Hualian earthquake $\left(M_{S}=7.6\right)$, J. Geomag. Geoelectr., 45, 251-259, 1993.

Everett, J. E. and R. D. Hyndman, Geomagnetic variations and electrical conductivity structure in southwestern Australia, Phys. Earth Planet. Int., 1, 24-34, 1967.

Fraser-Smith, A. C., A. Bernardi, P. R. McGill, M. E. Ladd, R. A. Helliwell, and O. G. Villard, Jr., Low-frequency magnetic field measurements near the epicenter of the Ms 7.1 Loma Prieta earthquake, Geophys. Res. Lett., 17, 1465-1468, 1990.

Fujinawa, Y. and K. Takanashi, Anomalous VLF subsurface electric field changes preceding earthquakes, Tech. Note Natl. Res. Inst. Earth Sci. Disast. Prev., 166, 61-75, 1994.

Fujita, S., Monitoring of time changes of conductivity anomaly transfer functions at Japanese magnetic observatory network, Mem. Kakioka Mag. Obs., 23, 53-87, 1990.

Fujiwara, S. and H. Toh, Geomagnetic transfer functions in Japan obtained by first order geomagnetic survey, J. Geomag. Geoelectr., 48, 10711101, 1996.

Gong, S. J., Anomalous changes in transfer functions and the 1976 Tangshan earthquake $\left(M_{S}=7.8\right)$, J. Geomag. Geoelectr., 37, 503-508, 1985.

Gutenberg, B. and C. F. Richter, Magnitude and energy of earthquakes, Annali di Geofisica, 9(1), 1-15, 1956.

Honkura, Y., Observations of short-period geomagnetic variation at Nakaizu (2): Changes in transfer functions associated with the IzuOshima-Kinkai earthquake of 1978, Bull. Earthq. Res. Inst., Tokyo, 54, 477-490, 1979.

Huang, Y. N., On the digital geomagnetic observatory at Lunping, Taiwan, Phys. Earth Plant. Inter., 59, 66-77, 1990.

Liu, J. Y., Y. I. Chen, Y. B. Tsai, and Y. J. Chuo, Seismo-ionospheric signatures prior to $M \geq 6.0$ Taiwan earthquakes, Geophys. Res. Lett., 27, 3113-3116, 2000.

Miyakoshi, J., Secular variation of Parkinson vectors in a seismically active region of Middle Asia, J. Faculty Gen. Education, Tottori Univ., 8, 209_ 218, 1975.

Nagao, T., Y. Enomoto, Y. Fujinawa, M. Hata, M. Hayakawa, Q. Huang, J. Izutsu, Y. Kushida, K. Maeda, K. Oike, S. Uyeda, and T. Yoshino, Electromagnetic anomalies associated with 1995 Kobe earthquake, $J$. Geodynamics, 33, 401-411, 2002.

Niblett, E. R. and Y. Honkura, Time-dependence of electromagnetic transfer functions and their association with tectonic activity, Geophys. Surv., 4, 97-114, 1980 .

Oike, K. and H. Murakami, On the relationship between shallow earthquakes and VLF noises, Tech. Note Natl. Res. Inst., Earth Sci. Disast. Pre., 157, 221-271, 1993 (in Japanese).

Pulinets, S. A., Seismic activity as a source of ionospheric variability, $A d v$. Space Res., 22, 903-906, 1998.

Rikitake, T., Changes in the direction of magnetic vector of short-period geomagnetic variations before the 1972 Sitka, Alaska, earthquake, $J$. Geomag. Geoelectr., 31, 441-448, 1979.

Rikitake, T., Earthquake precursors in Japan: precursor time and detectability, Tectonophysics, 136, 263-282, 1987a.

Rikitake, T., Magnetic and electric signals precursory to earthquakes: an analysis of Japanese data, J. Geomag. Geoelectr., 39, 47-61, 1987b.

Rikitake, T., Nature of electromagnetic emission precursory to an earthquake, J. Geomag. Geoelectr., 49, 1153-1163, 1997.

Sano, Y., Time changes of transfer functions at Kakioka related to earthquake occurrences (I), Mem. Kakioka Mag. Obs., 39(2), 1-25, 1980.

Scholtz. C. H. and R. Kranz, Notes on dilatancy recovery, J. Geophys. Res., 79, 2132-2135, 1974.

Scholtz, C. H., L. R. Sykes, and Y. P. Aggarwal, Earthquake prediction: a physical basis, Science, 181, 803-810, 1973.

Shiraki, M., Monitoring of the time change in transfer functions in the central Japan conductivity anomaly, J. Geomag. Geoelectr., 32, 637648, 1980.

Xu, W. Y., K. Qi, and S. M. Wang, On the short period geomagnetic variation anomaly of eastern Kansu province, Acta Geophys. Sinica, 21, 218-224, 1978 (Chinese with English abstract).

Yanagihara, K., Secular variation of the electrical conductivity anomaly in the central part of Japan, Mem. Kakioka Mag. Obs., 15, 1-11, 1972. 
Yanagihara, K. and T. Nagano, Time change of transfer function in the central Japan anomaly of conductivity with special reference to earthquake occurrences, J. Geomag. Geoelectr., 28, 157-163, 1976.

Yen, H. Y., C. H. Chen, Y. H. Yeh, J. Y. Liu, C. R. Lin, and Y. B. Tsai, Geomagnetic fluctuations during the 1999 Chi-Chi earthquake in Taiwan, Earth Planets Space, 56, 39-45, 2004.

Yoshino, T., I. Tomizawa, and T. Sugimoto, Results of statistical analysis of low-frequency seismogenic EM emissions as precursories to earthquakes and volcanic eruptions, Phys. Earth Planet. Inter., 77, 21-31, 1993.
Zeng, X., Y. Lin, C. Xu, and S. O. Yang, Turning changes in evolution of geomagnetic field and infrastructural analysis of earthquake prediction, Kybernets-Int. J. Systems \& Cybernetics, 30, 365-377, 2001.

Zeng, X., M. Hayakawa, Y. Lin, and C. Xu, Infrastructrual analysis of geomagnetic field and earthquake prediction, in Seismo Electromagnetics: Lithosphere-Atmosphere-Ionosphere Coupling, edited by M. Hayakawa and O. A. Molchannov, TERRAPUB, Tokyo, pp. 463-468, 2002.

K.-J. Chen (e-mail: kjchen@ntnu.edu.tw), B. Chiu, and C.-H. Lin 